\title{
CO-EXISTENT PULMONARY TUBERCULOSIS AND BRONCHOGENIC CARCINOMA
}

\author{
By A. D. IsaAcs, M.B., B.S. \\ Plaistow Hospital Chest Unit
}

\section{Introduction}

Pulmonary tuberculosis is being diagnosed more often in the later decades of life, namely, those in which bronchogenic carcinoma is known to be more common. The association of these two diseases is, in fact, being found with increasing frequency and is illustrated by the following case report.

\section{Case Report}

The patient first attended East Ham Chest Clinic in September 1953, when he was 68 years old. He complained of persistent cough for one year, which had been worse for the previous two months. It was associated with about an eggcupful of whitish sputum daily. He had experienced night sweats for one week, during which he complained of a pleuritic type of pain in the right chest.

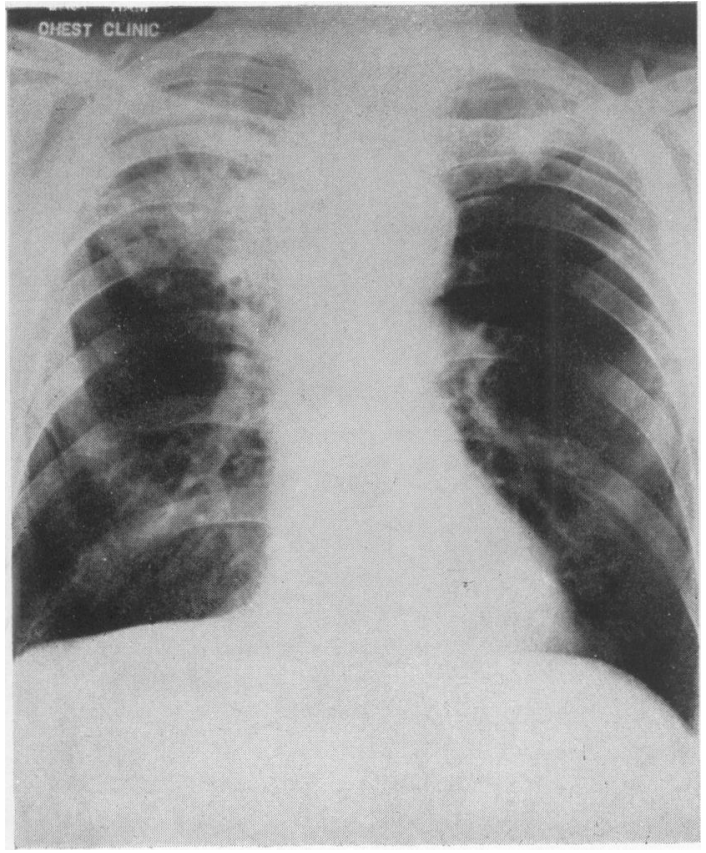

FIG. I
There was no relevant family history, and the only relevant detail in his previous medical history was that he had been graded $\mathrm{B}_{2}$ in 1914 on account of a 'shadow on the lung.'

On examination his general condition was poor; he was afebrile; his fingers were not clubbed. Physical examination of the chest showed it to be barrel-shaped with poor movement. The percussion note was impaired over the R.U.L. where medium crepitations were audible. Radiology of the chest showed the lungs to be emphysematous, and in addition there was infiltration and cavitation in the R.U.L. (Fig. I). The sputum was found to contain A.F.B.; the E.S.R. was $37 \mathrm{~mm}$. $/ \mathrm{hr}$.

A diagnosis of pulmonary tuberculosis was made and a course of chemotherapy instituted The response was good. Two months later the patient felt considerably better; there were no abnormal signs in the chest and there was definite

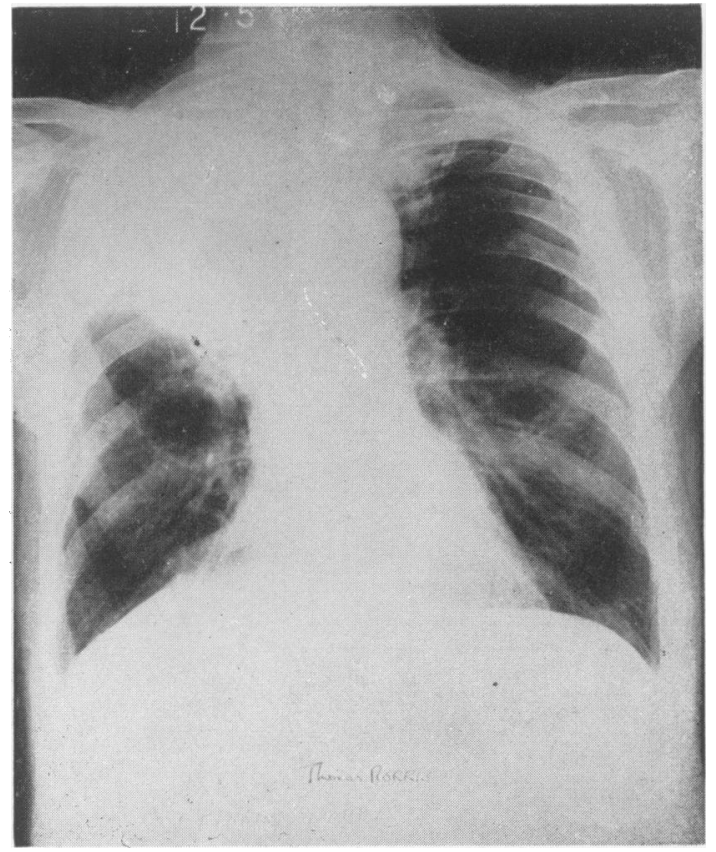

FIG: 2 
radiological evidence of resolution of the pulmonary lesion. Chemotherapy was continued, and he also received a period of in-patient treatment. $\mathrm{He}$ remained in good health. In April 1954, the sputum was found to contain A.F.B. on culture.

In May 1954, the patient complained of loss of weight, weakness and lack of energy. His appetite was poor and he felt generally unwell. Physical examination of the chest revealed the presence of definite signs over the right upper lobe -namely, impaired percussion note and tubular breathing. Radiography showed complete atelectasis of the R.U.L. (Fig. 2), associated with a rounded opacity at the right hilum which was clearly seen on tomography (Fig. 3).

$\mathrm{He}$ was bronchoscoped in July 1954, when a neoplasm was found obstructing the R.U.L. orifice, and the biopsy of this showed a ' necrotic undifferentiated carcinoma.'

The patient's general condition steadily deteriorated and he died in June 1955, one year after the diagnosis of carcinoma had first been made. Treatment during this period was purely symptomatic.

A post mortem showed a large necrotic neoplasm arising from the R.U.L. bronchus near the carina. The apex of the right lung was adherent to the chest wall and numerous small cavities were present. The remaining lung was congested and showed the changes of hypostatic pneumonia (Fig. 4).

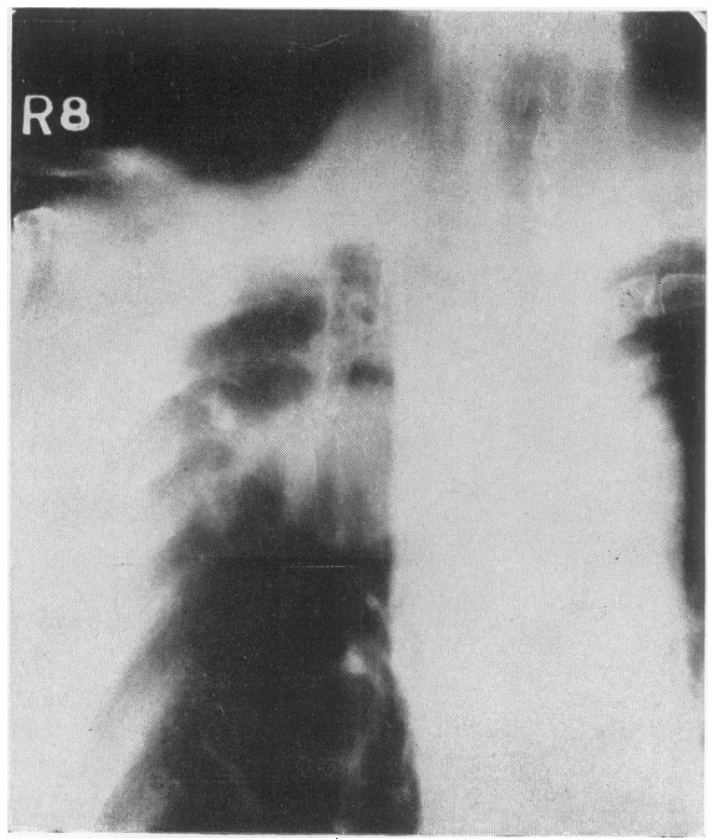

FIG. 3
Histological examination of the neoplasm: showed it to be a squamous celled carcinoma with keratinization and epithelial pearl formation.

The tuberculous nature of the cavitateda are $\stackrel{\infty}{\otimes}$ was also confirmed histologically.

\section{Comment}

In the above case the presence of chronic $\frac{\text { ? }}{5}$ fibrocaseous pulmonary tuberculosis was estab- $\frac{\overline{\bar{N}}}{\overline{0}}$ lished prior to the appearance of a bronchogenic $\frac{\bar{\sigma}}{\vec{\phi}}$ carcinoma at the same site. Divergent views have $\propto$ been expressed in the past about the association of $\stackrel{0}{\%}$ these two conditions. Heider (1866) thought $\vec{\circ}$ they were different manifestations of the same disease and MacConkie (1908) thought the $\vec{\omega}$ tubercle bacillus was the cause of both conditions. Conversely many writers have been convinced of

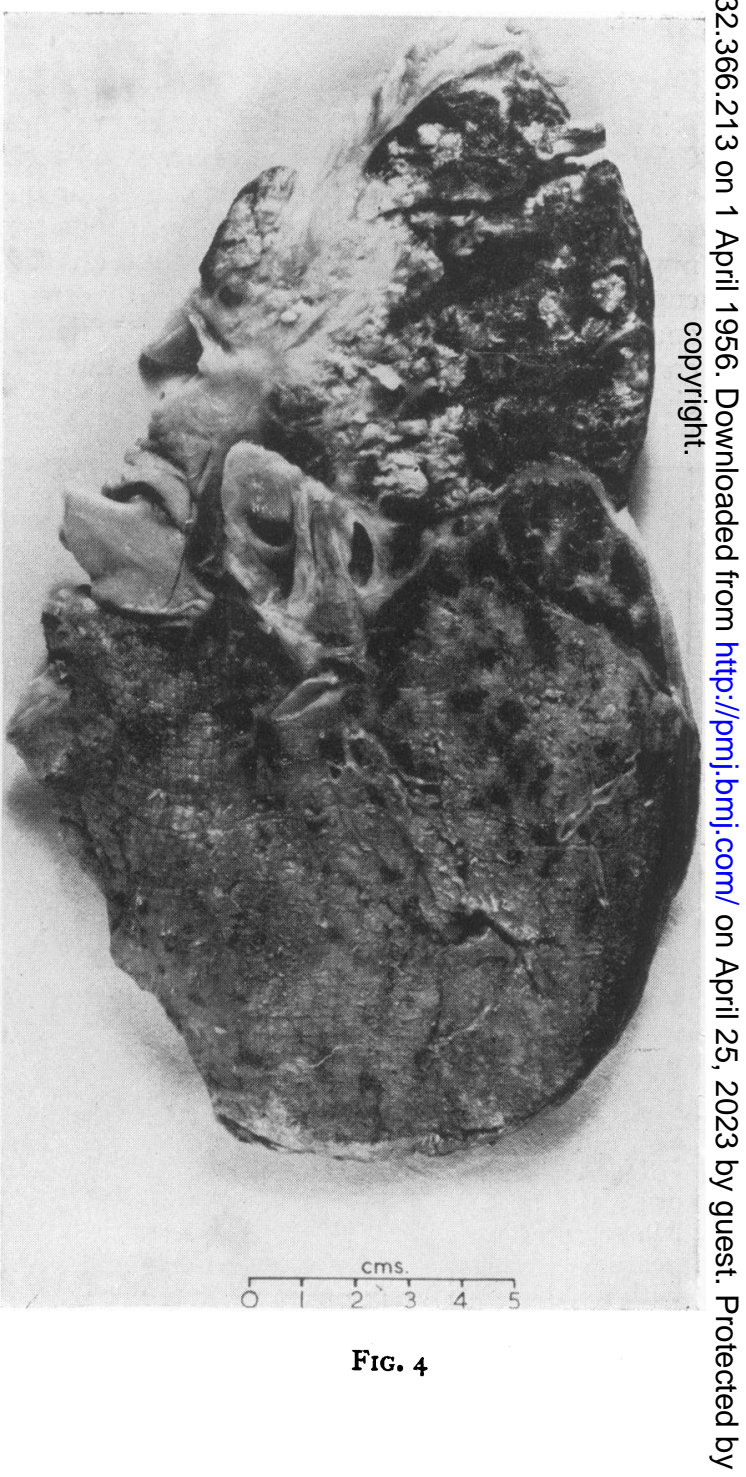


their mutual antagonism and on this basis Pearl (1929) suggested tuberculin as the treatment of bronchogenic carcinoma. There are several references in the literature to the association of the two conditions (Couts, I95I; Helm and Moon, I952; Ellman, 1953).

There is a significant difference in both prognosis and management, and the failure to recognize the presence of active pulmonary tuberculosis in association with carcinoma may produce a most unfavourable effect in the former condition. This applies especially to those patients subjected to radiotherapy, and the only effective treatment is resection of the lobe or lung affected (Ellman, 1953).

\section{Summary}

A case of co-existent pulmonary tuberculosis and bronchogenic carcinoma has been reported. The combination is being diagnosed with increasing frequency. and the importance of accurate diagnosis has been stressed.

\section{Acknowledgment}

I should like to extend my most grateful thanks to Dr. Philip Ellman for permission to publish details of this case and for his help and advice in this connection.

\section{BIBLIOGRAPHY}

COUTS, B. (1951), Tubercle, 32, 223.

EllmaN, P. (1953), Proc. Roy. Soc. Med., 46, 851 .

FREID, B. M. (1948), 'Bronchogenic Carcinoma and Adenoma,' London.

HELM, W. H. and MOON, A. J. (1952), Brit. F. Tuberc. and Dis. Chest., 46, 87.

PEARL, R. (1929), Amer. F. Hyg., 9, 97.

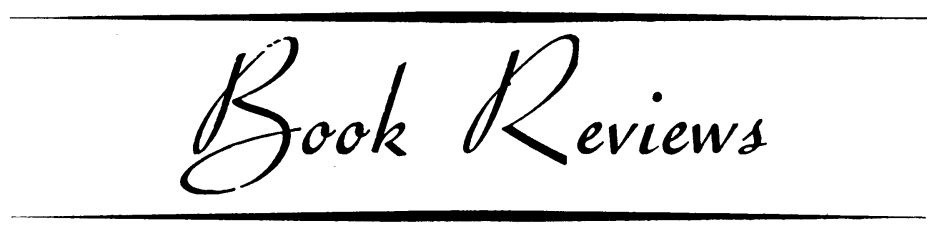

\section{MODERN ACTINOTHERAPY}

By R. H. Beckett, B.A. Pp. viii $+\mathrm{I} 6 \mathrm{I}$, with 20 illustrations and 4 colour plates. London: William Heinemann Ltd. 1955. 17s. 6d.

This book is an up-to-date review of the literature of ultraviolet and infra-red radiation.

An outline of the history of heliotherapy and ultraviolet therapy is given. The physics and physiological effects are discussed and the clinical applications of ultraviolet and infra-red radiation to dermatology, rheumatology, paediatrics and diagnosis described, with quotations from the literature and many useful references.

The book has the greatest interest for those engaged in physical medicine, whether doctors or physiotherapists, and should receive the interest of doctors in general in a rather neglected method of treatment.

\section{TEXTBOOK OF ORTHOPAEDIC MEDICINE Volume II. Treatment by Manipulation and Massage}

By James Cyriax, M.D., M.R.C.P. 5th Edition. Pp. xv +373 , with 127 illustrations. London: Cassell \& Co. Ltd. I955. 2is.

Dr. Cyriax's well-known book which was originally published in 1944 under the title 'Deep Massage and Manipulation Illustrated' has appeared in its fifth edition. The layout of the book with its clear and concise descriptions of technique, including exact site for massage, positioning of patient and physiotherapist, duration and frequency of treatment remains unchanged. It has been amplified to include a chapter on the local injection of hydrocortisone, one descriptive of the essential forms of massage students must learn, one on massage in plastic surgery and finally one on a modified form of the Bisgaard treatment of varicose ulcers.

Every section of the book is profusely and clearly illustrated with photographs.

In its new form it is an even more comprehensive book on technique and remains an essential textbook for physiotherapists and physiotherapy students.

\section{AN ATLAS OF BONE-MARROW PATHOLOGY}

By M. C. G. IsRaels, M.D., M.Sc., F.R.C.P. Second edition. Pp. $x+85$, with $\mathrm{I}_{3}$ colour plates. London: William Heinemann, Ltd. 1955. 3os.

Only very rninor changes and additions have been made in this, the second edition, after 7 years.

With the exception of the addition of the 'transitional megaloblast' the nomenclature remains the same; nobody can disagree with this. The text remains virtually the same, but the few modernising alterations in the bibliography have resulted in some faults in the reference numbers and some misprints have been taken over from the first edition. One new plate has been added. It is a very good one, but some of the red cells are printed in a yellow tint, producing a curious effect. The atlas is designed to stimulate the interest in bonemarrow studies.

E.N. 